The BMJ

Cite this as: BMJ 2020;370:m3558 http://dx.doi.org/10.1136/bmj.m3558 Published: 11 September 2020

\section{Operation Moonshot: What do the leaked documents say?}

\section{Elisabeth Mahase}

Operation Moonshot is the name of the UK government's newly proposed covid-19 mass testing scheme. The plan, revealed by The $B M J,{ }^{1}$ involves an expansion of testing from the current hundreds of thousands of tests each day to 10 million a day by early 2021. But how does the government propose to do this?

\section{How will testing increase between now and early 2021?}

The documents show a proposed three stage rollout. They state that the UK will carry out between 200 ooo to 800 ooo tests a day between September and December 2020. This might break down to:

- 200 ooo tests a day on people with symptoms,

- 100000 a day on people without symptoms in local areas to suppress outbreaks,

- 250000 a day on people without symptoms in the NHS and care homes, and

- 100000 a day through national prevalence studies.

From December the plans propose increasing daily capacity to between two and four million. This would involve mass testing of all homes in local areas or whole cities when prevalence rises ( 430000 tests a day), testing high contact professions such as teachers every week (100 ooo a day), and testing people to allow them to enter high risk settings, such as visitors to hospital and care homes.

The plan then states that there would be "full rollout" in early 2021 to 10 million tests a day, to "enable people to return to and maintain normal life." At this stage, weekly testing would be made available progressively to the whole population to allow people to go to high risk events by using a "digital passport" to show they have tested negative for the virus.

\section{How will testing capacity be increased?}

The documents talk about "buying large scale capabilities" from partners such as the drug company GSK to "build a large scale testing organisation." However, under "potential partners for increasing laboratory capacity" the documents list only the company AstraZeneca. Under logistics and warehousing, the documents list potential partners as Boots, Sainsbury's, DHL, Kuehne+Nagel, G4S, and Serco. Under workforce are listed universities, the Society of Microbiologists, and the British Society of Immunology.

Alongside mainly commercial partnerships, the documents also state that a number of new tests and technologies would need to be used, including some that do not yet exist.

"Delivering testing at the scale and level of ambition set by the prime minister is likely to mean developing, validating, procuring, and operationalising testing technology that currently does not exist," the plans state. Lower sensitivity testing for "screening/enabling purposes" could also be used, with polymerase chain reaction (PCR) testing then used to "confirm positive results or in situations where accuracy is needed for highest risk individuals."

Testing technology listed in the documents includes qrt-PCR, Endpoint PCR, LAMP, LamPORE, lateral flow antigen test, and whole genome sequencing. Two of these tests-lateral flow antigen tests and LAMP-are listed as having a "lower sensitivity" of between $80 \%$ and $100 \%$.

\section{Where will people get tested?}

The documents propose venues such as general practices and pharmacies, workplaces and schools, and community based local testing sites. ${ }^{2}$ Testing may also be carried out on site at events before people can enter.

\section{Are there any plans to get the public on board?}

The documents show that there have been discussions over how to incentivise people to be tested. They point to enforcing testing "via a sanction-based model" or through "offering individuals opportunities/access from being tested," such as being able to attend events.

\section{What is a digital passport?}

Testing for access to certain spaces features heavily in the documents, with reference to "immunity/virus free passports," likely to be available through an app. The plans say that testing could be used to "give people assurance that, at least for a limited time, they are unlikely to have the virus and are at low risk of transmitting it to others." 
They say, “A negative test result (or potentially a positive antibody result) may inform not just whether you could attend an in-patient appointment, but if you go to work that day, access a venue, get on a flight or visit an elderly relative.” The documents also point to a "significant expansion" of testing funded and delivered by the private sector, such as in football stadiums to allow access.

\section{Do the documents acknowledge any concerns?}

Yes, although not in great detail. In reference to the non-PCR tests, it is repeatedly noted that "new types of test are likely to be less accurate [than PCR], introducing some level of risk.” In terms of how testing would affect behaviour, the documents say that regular testing "might make people behave in safer ways, by building covid-safe routines into their daily lives, or less safely by giving false a degree of comfort.”

However, the documents also say, "We will need to take some risks, experiment and evaluate carefully, and find out what works and what does not."

\section{How will the $£ 100$ bn be spent?}

This figure is mentioned only briefly in the documents. They state that "opening up the economy" and allowing the population to "return to something closer to normality" would cost "over £1oobn to deliver.” The figure is not broken down.

\section{What reason does the government give for Moonshot?}

The documents state that the objective of the mass testing programme is to "utilise the full range of testing approaches and technologies to help reduce the $\mathrm{R}$ rate, keep the economy open and enable a return to normal life." They say that Moonshot has been described by the prime minister as the "only hope for avoiding a second national lockdown before a vaccine, something that the country cannot afford."

1 lacobucci G, Coombes R. Covid-19: Government plans to spend f100bn on expanding testing to 10 million a day. BMJ2020;370:m3520doi: 10.1136/bmj.m3520.

2 Mahase E. Operation Moonshot: GP clinics could be used to improve access to covid-19 tests. BMJ 2020;370:m3552.

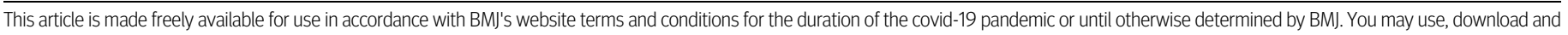
print the article for any lawful, non-commercial purpose (including text and data mining) provided that all copyright notices and trade marks are retained. 